\title{
Incidência da varíola, causada por Asperisporium caricae, em folhas de mamoeiros submetidos ao manejo orgânico, em diferentes ambientes de cultivo
}

\author{
Luiz Aurélio Peres Martelleto ${ }^{1}$, Raul de Lucena Duarte Ribeiro², Margarida Goréte Ferreira do Carmo², Mariluci \\ Sudo-Martelleto ${ }^{1,4}$, Antonio de Goes ${ }^{3,4}$
}

${ }^{1}$ PESAGRO-RIO/Estação Experimental de Macaé. Estrada Velha de Glicério km 3, CEP27901-970, Macaé/RJ.E-mail: martelleto@ pesagro.rj.gov.br ${ }^{2}$ UFRRJ, Instituto de Agronomia, BR 465 - km 07 - CEP 23890-000, Seropédica/RJ. ${ }^{3}$ FCAV/UNESP, Departamento de Fitossanidade, CEP 14884-900, Jaboticabal/SP. ${ }^{4}$ Bolsista CNPq. Parte da tese de doutoramento do primeiro autor.

Autor para correspondência: Antonio de Goes (agoes@fcav.unesp.br)

Data de chegada: 07/11/2007. Aceito para publicação em: 28/01/2009.

1550

\section{RESUMO}

Martelleto, L.A.P.; Ribeiro, R.L.D.; Carmo, M.G.F., Sudo-Martelleto, M.; Goes, A. Incidência da varíola, causada por Asperisporium caricae, em folhas de mamoeiros submetidos ao manejo orgânico em diferentes ambientes de cultivo. Summa Phytopathologica, v.35, n.4, p.288-292, 2009

Mudas de mamoeiro da cultivar Baixinho de Santa Amália foram transplantadas para covas de 40x60x40 cm, em áreas de três estruturas contíguas: (a) estufa sombreada (cobertura de plástico), (b) estufa sombreada + sombrite (cobertura adicional de sombrite com $30 \%$ de sombreamento sobre o plástico) e (c) telado (cobertura exclusiva de sombrite $30 \%$ ). Ao lado de tais estruturas foi implantada uma área de cultivo de mamoeiro em ambiente natural. Os tratos culturais aplicados foram os condizentes às normas técnicas vigentes na agricultura orgânica. As irrigações foram procedidas com mangueira plástica, evitando-se molhar folhas e frutos. Aos 45 dias pós-transplantio e, subseqüentemente, a intervalos mensais, as plantas foram inspecionadas em relação à incidência de lesões foliares causada pelo fungo
Asperisporium caricae. Para efeito de análise estatística, após o teste de homogeneidade das variâncias, foram consideradas quatro repetições por ambiente (tratamento), com seis plantas úteis por parcela. O modelo de quantificação da doença indicou efeito altamente significativo dos ambientes protegidos, estufa e estufa sombreada, quanto à incidência de sintomas, em comparação com ambientes de telado e em área natural de cultivo. Durante os 12 meses de avaliações foi constatada alta correlação entre incidência da doença e pluviosidade e umidade relativa do ar. As estruturas cobertas com plástico demonstraram alto potencial de controle de A. caricae, sendo, portanto, recomendáveis no sistema orgânico de produção do mamoeiro.

Palavras-chave adicionais: Carica papaya, agricultura orgânica.

\section{ABSTRACT}

Martelleto, L.A.P.; Ribeiro, R.L.D.; Carmo, M.G.F., Sudo-Martelleto, M.; Goes, A. Incidence of asperisporium black spot, caused by Asperisporium caricae, under organic management in different cropping environments. Summa Phytopathologica, v.35, n.4, p.288-292, 2009

Transplants of Baixinho de Santa Amália papaya cultivar were grown in three neighboring plant growth facilities: a) greenhouse (covered with plastic sheet); b) shaded greenhouse (with sombrite $30 \%$ black screen over the plastic sheet); c) screenhouse (covered with sombrite $30 \%$ only). Next to such structures a plot was settled for cultivation under natural environment. Cultural practices were conducted according to technical regulations for organic production. Irrigations were proceeded with plastic hose avoiding to wet leaves and fruits. From the $45^{\text {th }}$ day after transplanting and subsequently at monthly intervals the plants were monitored in relation to incidence of leaf lesions caused by the fungus Asperisporium caricae. For statistical analysis, after homogeneity of variance test, four repetition were considered within each ambient (= treatment), with six individuals for sampling. The model used for disease quantification indicated a highly significant effect of protected environments - greenhouse and shaded greenhouse - relating the reduction of leaf lesion numbers compared to screenhouse and natural cropping condition. Disease levels maintained a close correlation with rainfall and air relative humidity during the 12 months of evaluations. The plastic-covered structures showed high potential for controlling A. caricae on papaya leaves and may be recommended for papaya production in the organic system.

Keywords: Carica papaya, organic agriculture

A varíola ou asperisporiose do mamoeiro (Carica papaya L.), cujo agente causal é o fungo Asperisporium caricae (Speg.) Maubl., é doença de reconhecida importância para a cultura no Brasil, estando disseminada nas principais regiões produtoras, incluindo os estados do Espírito Santo, Bahia, Minas Gerais, Ceará e Paraná, dentre outros (8).
O nível de incidência da doença é marcadamente mais elevado durante épocas chuvosas ou quando há prolongado molhamento de folhas e frutos, favorecendo o processo de infecção. Sob condições severas, a doença reduz a área foliar fotossinteticamente ativa, com conseqüente perda de vigor da planta e redução do rendimento da cultura (1). 
A doença ocorre também no fruto, depreciando-o em termos de cotação de mercado e reduzindo a sobrevida pós-colheita, ou seja, o seu "tempo de prateleira", ao longo da cadeia produtiva. Bergamin Filho et al. (4) assinalam que, sob condições favoráveis ao patógeno, são indispensáveis aplicações freqüentes de fungicidas para reduzir os danos à produtividade e à qualidade dos frutos.

Não obstante os registros de que a doença representa sério problema para a cultura do mamoeiro no país $(2,5,10,11,13)$, pouco são os estudos realizados na busca de estratégias de controle integrado, capazes de minimizar seus efeitos prejudiciais (14). Tal dificuldade de controle mostra-se ainda mais evidente nos sistemas orgânicos de produção, dada aos escassos resultados de pesquisas e às restrições ao uso de agrotóxicos convencionais. Assim, diante do exposto, o cultivo do mamoeiro em ambiente protegido pode constituir-se em uma alternativa eficiente no controle de $A$. caricae, restringindo as condições favoráveis ao desenvolvimento e infecções do patógeno. Um maior investimento da produção orgânica de mamão mostra-se plenamente justificável face à alta demanda pela fruta, largamente utilizada, inclusive na alimentação infantil, agregando-se valores, dada à exclusão do uso de fungicidas, razão pela qual julgou-se oportuna a realização do presente trabalho.

\section{MATERIAL E MÉTODOS}

O estudo foi conduzido no Sistema Integrado de Produção Agroecológica - SIPA (Fazendinha Agroecológica km 47), município de Seropédica, Região Metropolitana do Rio de Janeiro (latitude de

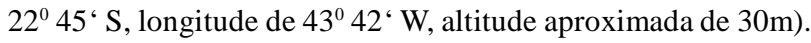

Construiu-se uma estrutura de proteção, tipo túnel, com $24,5 \mathrm{~m}$ de comprimento, 8,0 m de largura, pé-direito de 3,0 $\mathrm{m}$ e cumeeira atingindo $4,5 \mathrm{~m}$, coberta com polietileno de baixa densidade (PEBD) e revestida nas laterais, frente e fundo, com tela clarite anti-afídica (malha de 0,24 mm). Metade dessa estrutura foi adicionalmente revestida com tela sombrite (30\% de interceptação de luz) sobre o plástico. Dessa forma, foram obtidos dois ambientes de $12,25 \mathrm{~m}$ de comprimento por 8,0 m de largura, designados de estufa (E) e estufa sombreada (ES). Ao lado da estrutura descrita, montou-se um telado (T), com dimensões idênticas $(12,25$ x 8,0 m), com pédireito de 3,0 m, revestido apenas com sombrite $(30 \%$ de interceptação de luz). A área vizinha ficou reservada para cultivo em ambiente natural (AN) ou à céu aberto.

As mudas de mamoeiro foram produzidas em casa de vegetação do SIPA. Utilizaram-se sementes da cultivar Baixinho de Santa Amália, obtidas de duas plantas livres de viroses e apresentando alto potencial produtivo, que compunham um estande de mamoeiros sob manejo orgânico no SIPA.

O substrato de semeadura teve a seguinte composição volumétrica: três partes de subsolo argiloso:uma parte de esterco bovino curtido:1/2 parte de "cama" de aviário. Após homogeneização dessa mistura procedeu-se a sua distribuição em copos de material plástico, descartáveis, com capacidade volumétrica de $500 \mathrm{~mL}$. A semeadura deu-se em dezembro de 2003, depositando-se três sementes por recipiente. Após a germinação procedeu-se desbaste de plântulas, sendo mantidas as mais vigorosas, em cada um dos copos.

No centro das estufas e do ambiente de telado, a 1,80 m do nível do solo, foi colocado um termômetro de máxima e mínima e um psicrômetro, registrando-se diariamente as variações de temperatura máxima, mínima e umidade relativa do ar.
Depois da roçada da vegetação espontânea, foram preparadas 24 covas em cada ambiente, no espaçamento de $2,0 \mathrm{~m} \times 1,9 \mathrm{~m}$. O tamanho das covas foi de $60 \mathrm{~cm}$ x $40 \mathrm{~cm}$, com $40 \mathrm{~cm}$ de profundidade. O transplantio ocorreu no dia 03/03/2004, plantando-se três mudas/ cova.

As ervas espontâneas reinfestantes foram controladas por meio de cobertura morta (palha) e de roçadas periódicas. Visando proporcionar bom desenvolvimento das plantas e evitar o seu estresse hídrico ao longo da experimentação, procedeu-se o molhamento manual do colo das mesmas mediante emprego de mangueira plástica. Nessa operação evitou-se que a água atingisse a parte aérea das plantas e buscou-se a máxima uniformidade da sua distribuição, entre os tratamentos.

As plantas foram mensalmente adubadas com "cama" de aviário (1,5 L/cova) e bimensalmente com sulfato de potássio (50 g/cova). Pulverizações quinzenais foram alternadamente procedidas com o biofertilizante Agrobio a $2 \%$ e com calda bordalesa a $1 \%$, ambos formulados localmente, na Estação Experimental de Seropédica (Pesagro-Rio), conforme descrito por Fernandes (6).

O controle preventivo de ácaros foi realizado mediante pulverizações de calda sulfocálcica a $1 \%$ v/v, enquanto que o da mosca branca deu-se com uma formulação comercial à base de óleo de Neem $(0,5 \%)$. Armadilhas luminosas foram também empregadas para reduzir a população de cigarrinhas.

Após a sexagem das plantas, foram eliminadas as plantas fêmeas e assegurou-se $100 \%$ de plantas hermafroditas, sendo mantida uma única delas em cada cova. Para efeito de análise de variância dentro de cada tratamento (ambiente de cultivo), foram consideradas quatro parcelas, correspondendo às linhas de cultivo do mamoeiro, espaçadas de 2,0 m entre si, com seis indivíduos por parcela.

Para comparar o efeito dos ambientes em relação à manifestação da doença nas folhas de mamoeiro, considerou-se a variância dentro de cada tratamento, em conformidade com a metodologia preconizada por Pimentel-Gomes (12).

Com base nos dados mensais de número de lesões por folíolo foi calculada a incidência média de lesões para cada ambiente e a relação entre a incidência média em cada ambiente protegido e ambiente natural. Efetuou-se, ainda, análise de correlação de Pearson entre os valores mensais de número de lesões por folíolo e os valores médios de temperatura, amplitude térmica, umidade relativa do ar e de pluviosidade.

Na terceira semana de cada mês, a partir do $15^{0}$ dia após o transplantio das mudas, até completar um ano, quantificou-se a intensidade de sintomas de varíola nas folhas, em 100\% das plantas. Para tal, procedeu-se contagem do número de lesões necróticas no folíolo principal da folha-índice, correspondendo à sexta folha ativa a contar da folha mais nova já emitida (6).

No transcorrer da experimentação, mensalmente foram tomados os dados relativos a: (i) altura das plantas (do solo até a gema apical), (ii) diâmetro basal do tronco (medido a $15 \mathrm{~cm}$ do nível do solo), (iii) número médio de folhas ativas e, (iv) área foliar. Para a determinação da área foliar tomou-se como referência a folha $\mathrm{A}$, a qual foi estimada a partir da nervura principal da folha-referência (folha a qual, no dia da avaliação, possuía em sua axila uma flor em antese), conforme metodologia de Alves \& Santos (3). Ao longo dos 12 primeiros meses de colheitas, semanalmente foram avaliados o número e peso de todos os frutos comercializáveis. Frutos petândricos, carpelóides e aplastados, assim como os com elevados níveis de sintomas de varíola e mancha fisiológica foram descartados. 


\section{RESULTADOS E DISCUSSÃO}

Ocorreu heterocedasticidade entre as variâncias dos tratamentos em diversas épocas de amostragem. Em termos médios, a incidência e severidade dos sintomas causados por A. caricae, computados após um ano, adequaram-se à comparação do efeito dos diferentes ambientes de cultivo do mamoeiro.

O efeito dos ambientes na manifestação dos sintomas mostrou-se evidente a partir de dois meses após o transplantio das mudas, com maior número de lesões por folíolo nas plantas cultivadas no ambiente natural (Figura 1).

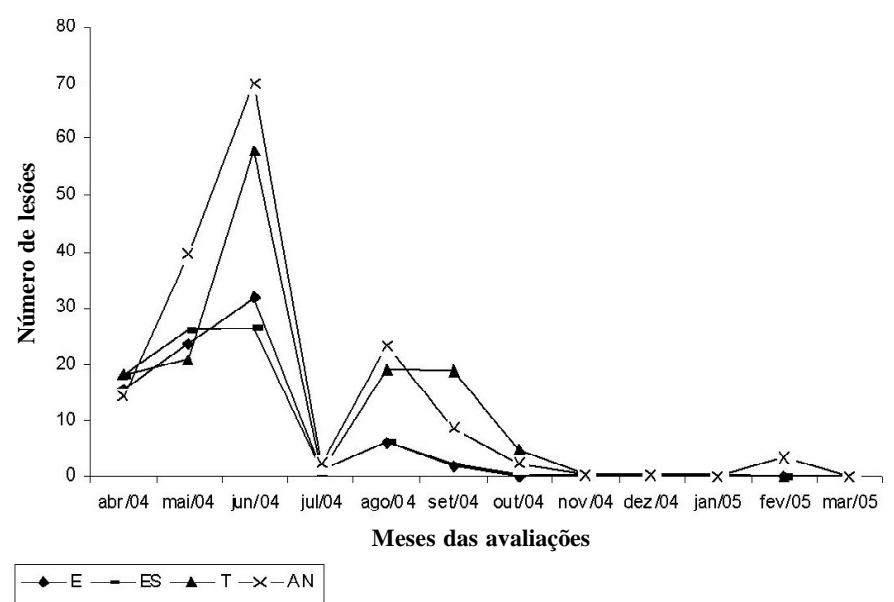

Figura 1. Efeito do tipo de ambiente $(\mathrm{E}=$ estufa, $\mathrm{ES}$ = estufa sombreada, $\mathrm{T}=$ telado e $\mathrm{AN}=$ ambiente natural) sobre o número de lesões causadas por Asperisporium caricae, presentes no folíolo principal da folha-índice do mamoeiro (sexta folha ativa a contar da folha mais nova já aberta), cultivado em sistema orgânico de produção. Seropédica-RJ, 2004/2005.

Conforme dados contidos na Figura 1, observa-se que houve um incremento na quantidade de doença, em termos de número de lesões na folha-índice, nos meses de agosto e setembro de 2004, não obstante a incidência da mesma tenha se situada próximo de zero no mês de julho desse ano. Essa elevação do índice de doença aparentemente deu-se em razão de um incremento da quantidade de inóculo no mês de julho, em detrimento da maior quantidade de chuva observada nesse mês, acompanhado de temperatura mais amena e elevado teor de umidade relativa do ar (Figura 2). Tais fatores certamente contribuíram para uma maior esporulação do patógeno, sendo os reflexos observados nos meses subseqüentes. A importância de tais parâmetros climáticos mostra-se evidenciada conforme dados contidos na Tabela 1, fato esse que dá, também, sustentação à hipótese apresentada.

Nas avaliações realizadas nos meses de julho a outubro de 2004, verificou-se que o efeito entre os tratamentos mostrou-se muito evidente, tornando possível a distinção das diferenças resultantes dos ambientes cobertos com plástico, em relação a ambiente de telado e ambiente natural, onde a incidência da doença foi mais elevada. Nos meses subseqüentes, correspondentes ao período entre outubro de 2004 até março de 2005, o nível de doença foi baixo, não havendo diferenças significativas entre os tratamentos.

Quanto ao número de lesões necróticas na folha-índice do mamoeiro, houve efeito significativo dos ambientes constituídos por estufa e estufa sombreada, com redução superior a $50 \%$, em comparação com a incidência observada nos mamoeiros sob ambiente natural (Tabela 2). Por outro lado, no cultivo sob ambiente telado a redução da incidência foi de cerca de $14 \%$, quando comparada com o cultivo sob ambiente natural. Mesmo no período de maior incidência dos sintomas da doença, esses níveis de redução mantiveram-se proporcionais e acentuados.

Nos três primeiros meses subseqüentes ao pós-transplantio das mudas (abril, maio e junho de 2004), independentemente do ambiente de cultivo o número de lesões na folha-índice atingiu valores muito mais elevados do que nos demais meses correspondentes ao restante do período de avaliação, que se estendeu até março de 2005. Por ocasião do transplantio, as folhas das mudas já se mostravam infectadas, cujo inóculo inicial certamente contribuiu para o incremento e expressão dos sintomas nos meses iniciais de cultivo.

Os valores dos índices de doença na folha-índice, em julho de 2004, aproximaram-se de zero, resultantes, portanto, da influência dos fatores climáticos (Figura 2) sobre o desenvolvimento do patógeno e subseqüente expressão de sintomas. Observou-se que a quantidade de doença até a sexta folha ativa aparentemente não acompanhou, proporcionalmente, o incremento de crescimento vegetativo das plantas, notadamente das folhas, tão logo as mudas transplantadas tiveram acesso aos nutrientes disponibilizados pela adubação. Admitese que o intenso lançamento de folhas pelas plantas, nos primeiros meses de cultivo, certamente contribuiu para uma melhoria do nível de

Tabela 2. Incidência da varíola ( $n^{\circ}$ de lesões necróticas) na folha-índice ${ }^{1}$ do mamoeiro 'Baixinho de Santa Amália' submetido ao manejo orgânico, em diferentes ambientes de cultivo. Seropédica-RJ, 2004/2005

\begin{tabular}{lcc}
\hline $\begin{array}{l}\text { Ambiente } \\
\text { de cultivo }\end{array}$ & $\begin{array}{c}\text { Incidência } \\
\text { da varíola }\end{array}$ & $\begin{array}{c}\text { Redução da } \\
\text { incidência }(\%)^{\mathbf{3}}\end{array}$ \\
\hline Estufa & $6,7 \mathrm{~b}$ & $-51,3$ \\
Estufa sombreada & $6,8 \mathrm{~b}$ & $-50,5$ \\
Telado & $11,8 \mathrm{a}$ & $-13,7$ \\
Ambiente natural & $13,7 \mathrm{a}$ & -- \\
DMS & 2,3 & \\
\hline CV $(\%)$ & 31,5 \\
\hline
\end{tabular}

${ }^{1}$ Sexta folha ativa, a contar da folha mais nova já emitida; ${ }^{2}$ Os valores representam a média anual do número de lesões por folíolo principal da folha-índice de 24 plantas por tratamento (= ambiente de cultivo); letras iguais indicam médias que não diferem entre si (Tukey, $P \leq 0,05) .{ }^{3}$ Comparação entre os ambientes protegidos e o ambiente natural de cultivo.

Tabela 1. Correlações entre fatores climáticos e níveis de incidência da varíola ( $\mathrm{n}^{\circ}$ de lesões necróticas) na folha-índice ${ }^{1}$ do mamoeiro 'Baixinho de Santa Amália' submetido ao manejo orgânico, em diferentes ambientes de cultivo. Seropédica-RJ, 2004/2005

\begin{tabular}{lcccc}
\hline \multirow{2}{*}{ Ambiente de cultivo } & \multicolumn{3}{c}{ Fator climático } \\
\cline { 2 - 5 } & Pluviosidade & Temperatura ambiente & Amplitude térmica & Umidade relativa do ar \\
\hline Estufa & $0,773^{* *}$ & $-0,357$ & 0,492 & $0,528^{\text {ns }}$ \\
Estufa sombreada & $0,810^{* *}$ & $-0,266$ & 0,519 & $0,866^{* *}$ \\
Telado & 0,463 & $-0,428$ & 0,470 & $0,526^{\text {ns }}$ \\
Ambiente natural & $0,607^{*}$ & $-0,448$ & 0,435 & $0,607^{*}$ \\
\hline
\end{tabular}

${ }^{1}$ Sexta folha ativa, a contar da folha mais nova já aberta; ${ }^{2}$ Correlações baseadas no confronto mês a mês entre a quantidade de doença e cada fator climático; *Valor significativo pelo teste t a $5 \%$; **Valor significativo pelo teste $\mathrm{t}$ a $1 \%$. 

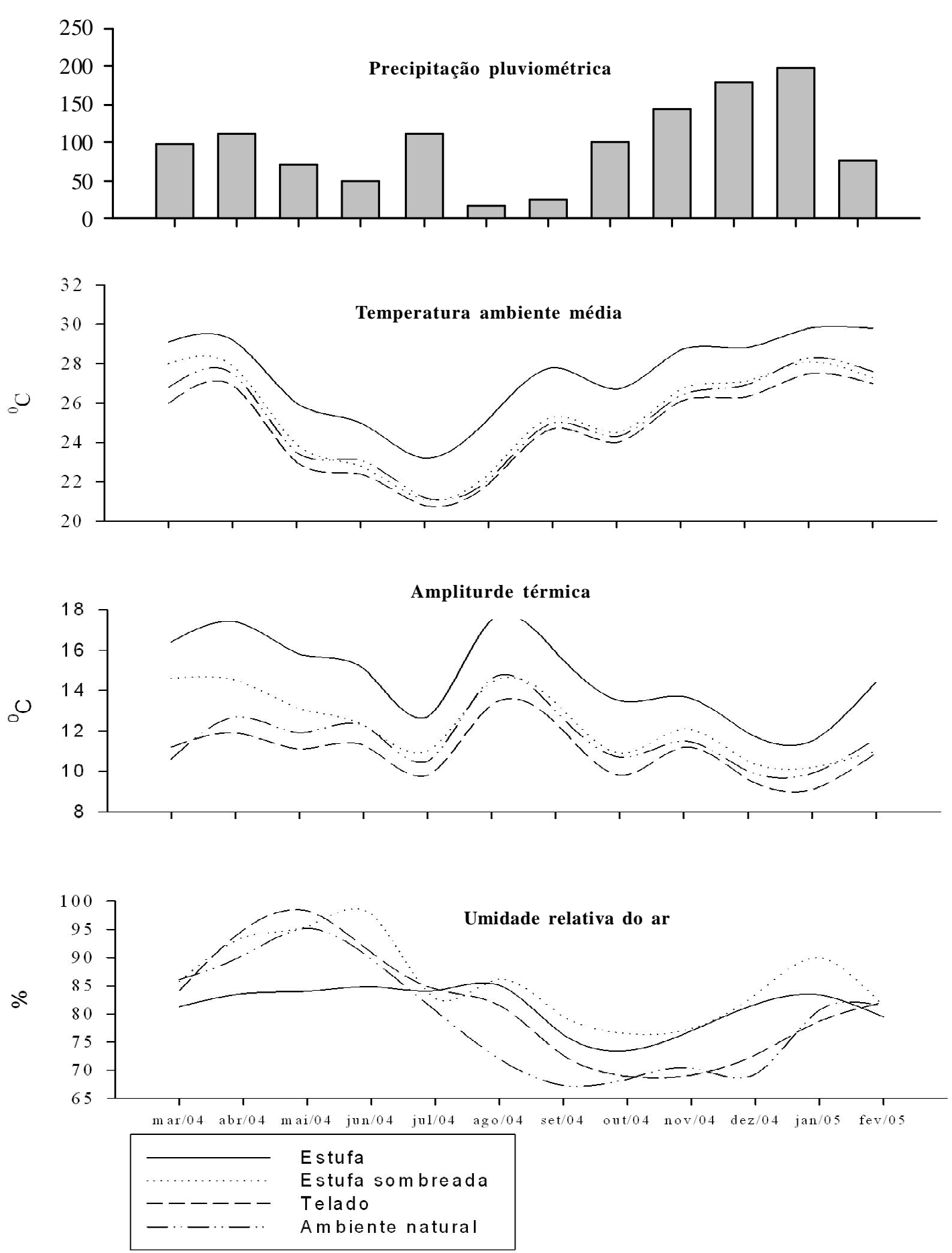

Figura 2. Precipitação pluviométrica (Fonte: Pesagro-Rio/EES) e valores de temperatura ambiente, amplitude térmica e umidade relativa do ar registrados em cada ambiente de cultivo de mamoeiros, ao longo de 12 meses. Seropédica-RJ, 2004/2005.

resistência natural das plantas, redundando em menores quantidades de doença nos primeiros meses de cultivo.

Em termos de desenvolvimento vegetativo foi observado diferença estatística entre os tratamentos, independente da variável avaliada (Tabela 3). Em termos gerais, em ambientes de estufa e estufa sombreada foram obtidos plantas mais altas, maior diâmetro do tronco e maior área foliar. A menor média de folhas funcionais observada no ambiente externo, seguido do telado, se deveu, sobretudo, à ocorrência de varíola das folhas, antecipando sua senescência.

Em termos de influência no desempenho agronômico, Martelleto 
e colaboradores (9) observaram que a cv. Baixinho de Santa Amália, quando cultivado em ambiente protegido (estufa tipo túnel) apresentou aumento significativo na produção quando comparado ao ambiente natural de cultivo. Por outro lado, em ambiente de proteção cobertos com tela sombrite (30\% de interceptação da luz solar) há interferência negativa no vigor das plantas, com conseqüente redução de produção.

A quantificação da quantidade de doença mediante contagem do número de lesões presentes na sexta folha ativa, ainda que considerando as variáveis envolvidas, permitiu concluir que os ambientes protegidos (estufa e estufa sombreada) proporcionaram condições de microclima desfavorável ao desenvolvimento de $A$. caricae, representando uma alternativa promissora para o cultivo de mamoeiro em sistema de cultivo orgânico, possibilitando, assim, atender as normas técnicas preconizadas pela agricultura orgânica.

Os resultados aqui descritos corroboram aos de Adikaram \& Wijépala (1) e Rezende \& Fancelli (11), os quais postularam que o fungo $A$. caricae mostra-se mais severo durante períodos chuvosos e em regiões com prevalência de alta umidade relativa do ar. Dessa forma, considerando-se que o desfolhamento prematuro do mamoeiro devido à varíola mostra-se como um fator limitante da produtividade, principalmente em sistemas de cultivos orgânicos, o cultivo sob ambiente protegido reúne potencial técnico promissor, não obstante o investimento adicional requerido na montagem das estruturas de proteção.

\section{AGRADECIMENTOS}

À Universidade Federal Rural do Rio de Janeiro, particularmente ao programa de Pós-Graduação em Fitotecnia, por disponibilizar os recursos necessários para a construção das estruturas de proteção e à PESAGRO-RIO/EES, pela relevante contribuição na montagem das mesmas.

\section{REFERÊNCIAS BIBLIOGRÁFICAS}

1. Adikaram, N.K.B.; Wijépala, M. Aspersiporium black spot in Carica papaya: a new disease in Sri Lanka. Journal of the National Science council of Sri Lanka, Colombo, v.23, n.4, p.213-219, 1995.
2. Almeida, D. L. de; Ribeiro, R. de L. D.; Guerra, J. G. M. Sistema integrado de produção agroecológica: "Fazendinha Agroecológica km 47”. In: Simpósio de Agricultura Ecológica, 2.; Encontro de Agricultura Orgânica, 1999, São Paulo. Anais...Guaíba: Agropecuária, 1999. p.153-159.

3. ALVES, A.A.C.; SANTOS, E.L. Estimativa de área foliar do mamoeiro: método não-destrutivo. In: CONGRESSO BRASILEIRO DE FRUTICULTURA, 17., 2002, Belém, 2002. 1 CD-ROM.

4. Bergamin Filho, A.; Jesus Júnior, W.C. de; Amorim, L. Danos causados por doenças em fruteiras tropicais. In: Zambolim, L. Manejo integrado de fruteiras tropicais: doenças e pragas. Viçosa: Impressa da Universidade de Viçosa, MG, 2002. p. 47-69.

5. Chiacchio, F. P. B. Doenças em fruteiras: mamão. Informe Agropecuário, Belo Horizonte, v.11, n.123, p.27-30, 1985.

6. Fernandes, M. do C. de A. O biofertilizante agrobio. A Lavoura, Rio de janeiro, v.103, n.634, p.42-43, 2000.

7. Ide, C.D; Martelleto, L.A.P., Marin, S.L.D.; Yamanishi, O.K. Resposta de diferentes genótipos de mamoeiro à manifestação de varíola. Comunicado Técnico PESAGRO-RIO, n. 259. 2001. $6 \mathrm{p}$.

8. Liberato, J.R.; Zambolim, L. Controle das doenças causadas por fungos, bactérias e nematóides em mamoeiro. In: Zambolim, L.; Vale, F. X. R.; Monteiro, A.J.A.; Costa, H. Controle de doenças de plantas: fruteiras - Viçosa, 2002. v.2., p.1023-1138.

9. Martelleto, L.A.P.; Ribeiro, R.L.D ; Martelleto, Mariluci Sudo; Vasconcellos, M.A.S.; Marin, S.L.D.; Pereira, M.B. Cultivo orgânico do mamoeiro 'Baixinho de Santa Amália' em diferentes ambientes de proteção. Revista Brasileira de Fruticultura, Jaboticabal, v.30, p.662-666, 2008.

10. Nishijima, W. T.; Dickman, M. B.; KO, W. H.; Ooka, J. J. Papaya diseases caused by fungi. In: Ploez, R. C.; Zentmyer, G. A.; Nishijima, W. T.; Rohrback, K. G.; Ohr, H. D. Compendium of tropical fruit diseases. St. Paul: American Phytopathological Society, 1994. p.58-64.

11. Oliveira, A. A. R.; Santos Filho, H. P. Doenças. In: Ritzinger, C.H.S.P.; Souza, J. da S. (Org.) Mamão: fitossanidade. Brasília: Embrapa Comunicação para Transferência de Tecnologia, 2000. p. 37-46.

12. Pimentel-Gomes, F. Curso de estatística experimental. Piracicaba, ESALQ, 2000. 477p.

13. Rezende, J.A.M.; Fancelli, M.I. Doenças do mamoeiro (Carica Papaya L.). In: Kimati, H.; Amorim, L.; Bergamin Filho, A; Camargo, L.E.A., Rezende, J.A.M. (Ed.). Manual de fitopatologia: doenças das plantas cultivadas, 3.ed. São Paulo: Agronômica Ceres, 1997. p.486-496.

14. Santos, M.C. dos; Barreto, M. Estudos epidemiológicos da varíola do mamoeiro em cultivares submetidas a tratamentos com fungicidas. Summa Phytopathologica, Jaboticabal, v.29, p.141-146, 2003. 